\title{
Influence of Polyphosphate Hydrolysis on the Degradation of Volatile Fatty Acids (VFAs) in Anaerobic Digestion
}

\author{
Ikechukwu Maxwell Onoh1*, Gordian Onyebuchukwu Mbah², Albert Chibuzo Agulanna3 \\ ${ }^{1}$ Chemical and Bioprocess Engineering Department, Hamburg University of Technology (TUHH), Harburg, Germany \\ ${ }^{2}$ Chemical Engineering Department, Enugu State University of Science and Technology (ESUT), Enugu, Nigeria \\ ${ }^{3}$ Materials and Energy Technology Department, Projects Development Institute (PRODA), Emene Industrial Area, Enugu, Nigeria \\ Email: ^maxcalab001@gmail.com,mbagordian@yahoo.com, acagulanna@yahoo.com
}

How to cite this paper: Onoh, I.M., Mbah, G.O. and Agulanna, A.C. (2017) Influence of Polyphosphate Hydrolysis on the Degradation of Volatile Fatty Acids (VFAs) in Anaerobic Digestion. Advances in Chemical Engineering and Science, 7, 439-449. https://doi.org/10.4236/aces.2017.74031

Received: July 6, 2017

Accepted: October 20, 2017

Published: October 23, 2017

Copyright $\odot 2017$ by authors and Scientific Research Publishing Inc. This work is licensed under the Creative Commons Attribution International License (CC BY 4.0).

http://creativecommons.org/licenses/by/4.0/

\begin{abstract}
The degradation rate of Volatile Fatty Acids (VFAs) produced predominantly in the acidogenesis stage is a key process parameter to be optimised to ensure a successful Anaerobic digestion (AD). Thermodynamically, the oxidation of the VFAs are energetically unfavourable, and as such external energy source apart from the energy derived from the hydrolysis of Adenosine Triphosphate (ATP) is needed for the initial activation of the VFAs, initial growth of the methanogens in $\mathrm{AD}$ process and improved degradation rate of the VFAs. Thus, this research investigated the influence of polyphosphate hydrolysis on the degradation rate of the VFAs at high concentration. Sodium-propionate, Sodium-butyrate and Sodium-acetate salts were added at the start of experiments in order to increase the concentration of the VFAs. The polyphosphate salts used were; $\mathrm{Na}$-hexametaphosphate, $\mathrm{Na}$-tripolyphosphate and potassium pyrophosphate. The control experiment was polyphosphate free and three process parameters (degradation rate, cumulative biogas production and specific methane content) of anaerobic digestion were investigated. The experiments were carried out at a mesophilic temperature of $37.5^{\circ} \mathrm{C}$ for 41 days. The results of the investigation showed that the treated reactors with the polyphosphate salt solution in low concentration performed better than the reactors with high concentration of the polyphosphate salts solution. All the treated reactors with poly-P salts performed better than reactor Nr-9 (control experiment), but reactor $\mathrm{Nr}-1$ was outstanding with an improved degradation rate of $47 \%$, cumulative biogas production of $21 \%$ and specific methane content of $23 \%$.
\end{abstract}

\section{Keywords}

Volatile Fatty Acids (VFAs), Polyphosphate Salts, Anaerobic Digestion, 
Bioenergetics, Syntrophic Degradation

\section{Introduction}

Energy production by anaerobic digestion of animal slurries, sewage sludge, plant residues or wastewater is a major task for a sustainable future development [1]. Digestion connected with biogas production may play a triple part. First, it is a method of converting the energy contained in biomass into useful fuel (biogas) which may be stored and transported. Second, it is a method of recycling of organic wastes into stable soil additives, that is, valuable liquid fertilizer and energy. Third, it is a method of waste treatment aimed at a reduction of their hazardous effects on the environment [2] [3]. Anaerobic degradation of organic matters proceeds via four major steps; hydrolysis, acidogenesis, acetogenesis and methanogenesis. These steps involve the actions of hydrolytic/fermentative bacteria, syntrophic/acidogenic bacteria, acetogenic bacteria $(\mathrm{AB})$ and methanogenic bacteria (MB) respectively. The whole anaerobic digestion process can be influenced by varying factors. It can be differentiated basically according to influences: which are caused by the effects on the enzymatic system of the participating organisms (temperature, $\mathrm{pH}$ values, metabolites etc); which are determined by reaction kinetics (mixing, retention time, reactor size etc); which are caused by the composition of the substrate and the intermediate products, especially volatile fatty acids from acidogenesis stage [1].

The concentration of the volatile fatty acids (VFAs) is one of the most important parameters in the monitoring of anaerobic digestion process. It is commonly agreed that VFA build-up is the result of unbalanced digestion conditions [4]. The decrease in $\mathrm{pH}$ accompanying accumulation of VFAs is the main cause of toxicity and reactor failure in the anaerobic digestion process [5].

During phases of overloading or inhibition, the anaerobic food-chain is unbalanced and fatty acids such as acetate, butyrate or propionate accumulate [6]. Overloading may occur during start-up periods, when hydrogenotrophic methanogens fail to consume the hydrogen that is produced during fermentation and acetogenesis and leads to accumulation of fatty acids [7]. Once propionate or butyrate has been formed by acidogenic bacteria, acetogenic bacteria are essentially necessary for further anaerobic degradation. Anaerobic oxidation of propionate by acetogenic bacteria is only possible, if the hydrogen and formate concentrations are kept extremely low [8], e.g. by the action of syntrophic hydrogen or formate utilizing bacteria such as methanogens or sulphate reducers. The majority of anaerobic propionate oxidizing bacteria use the methyl-malonyl-CoA pathway, yielding acetate, $\mathrm{CO}_{2}$ and $\mathrm{H}_{2}$, but a second pathway is also possible which leads to butyrate and acetate production [8], which implies that the methanogens must consume the acetate in the solution for further degradation of the propionate. 
In an actual reactor, there are various VFAs and their cooperative effects need to be taken into account. It was considered that VFA concentration above 2000 $\mathrm{mg} \cdot \mathrm{L}^{-1}$ led to inhibition of cellulose degradation, while VFA concentration above $4000 \mathrm{mg} \cdot \mathrm{L}^{-1}$ caused only feeble inhibition of glucose degradation [9]. In addition, many researchers have considered that HPa accumulation would inhibit the activity of $\mathrm{MB}$ and lead to cessation of fermentation.

The degradation of the volatile fatty acids (VFAs) such as propionic and butyric acids require an initial biochemical energy input. The syntrophic energy between acid degraders and hydrogen and formate removers is not sufficient to drive the oxidation of these VFAs. Hence, the acid degraders must hydrolyse ATP to generate the requisite energy. ATP hydrolysis is strictly biochemically regulated and only coupled to thermodynamically unfeasible reaction to ensure forward reaction. ATP is a polyphosphate molecule; and the important reaction of ATP in biochemical processes is the breaking of the terminal bond of the pyrophosphate moiety in a hydrolysis reaction for energy release. The energy is used by the micro-organisms for the initial activation and degradation of the VFAs with special interest on degradation of propionic and butyric acids [9] [10] [11] [12] [13].

This research was aimed at the optimization of the anaerobic process, by enhancing the degradation rate of high volatile fatty acids concentration (VFAs). The inorganic acids that were added as VFAs supplements in order to increase their concentration at start-up of the experiments were; sodium-butyrate, sodium-propionate and sodium-acetate, each at high concentration, while the polyphosphate salts used were; sodium tripolyphosphate, Sodium Hexametaphosphate and Potassium pyrophosphate. The result from a previous investigation unpublished [14] using biogas yield as an indicator of degradation, suggests that significant improvement in VFAs degradation rate could be achieved with auxiliary energy from polyphosphate hydrolysis in low concentration under acidic condition.

Therefore this research investigated the bioenergetics and influences of polyphosphate hydrolysis on propionate and butyrate degradation as well as acetate metabolism as it relates to biogas production with specific interest on methane yield in an anaerobic digestion.

\section{Materials and Method}

\section{1) SUBSTRATES}

The base substrate used in this experiment was maize silage, which was also the inoculum. Sodium propionate, Sodium butyrate and Sodium acetate salts were added to increase the concentration of the Volatile fatty acids (VFAs) in the system, which were part of the substrates. Hence, the maize silage digestate comprises a mixture of the following (Table $1 \&$ Table 2).

2) EXPERIMENTAL SET-UP: The test system comprises a water bath made of polypropylene containing distilled water; and thermostat placed in the water 
Table 1. Composition of the substrate used for the experiments.

\begin{tabular}{ccc}
\hline Composition of the Maize Silage & Mass (g) & Proportion (\%) \\
\hline Maize Silage & 30 & 75 \\
Lawn Grass Cuttings & 6 & 15 \\
Wine Residue (Tester) & 2 & 5.0 \\
Cow Manure (Milking Cow) & 1 & 2.5 \\
Others & 1 & 2.5 \\
\hline
\end{tabular}

Source: Institute of wastewater management and water protection Lab., TUHH Germany.

Table 2. Amount of VFAs supplement added per Reactor.

\begin{tabular}{cc}
\hline VFAs Supplement & Mass Concentration $(\mathrm{g} / \mathrm{l})$ \\
\hline Sodium Acetate & 5.00 \\
Sodium Propionate & 8.42 \\
Sodium Butyrate & 1.646 \\
\hline
\end{tabular}

Source: Institute of wastewater management and water protection Lab., TUHH Germany.

bath which was set to a temperature of $37.5^{\circ} \mathrm{C}$. Other components include; a metal frame with an upper and lower shelf, 9 1-liter aspirator bottles, tubing materials and 9 eudiometers. The 91 -litre aspirator bottles (reactors), each with 1 lower- and 2 upper nozzles, are connected through one of the upper nozzles to 9 graduated glass eudiometers: each bottle reactor to a eudiometer. The free nozzle was available for sample collection using a syringe with a lure lock. The nozzles have GL-14 thread to match a GL-14 plastic cap with a bore that is sealed with a three-layer septum. The nozzle that connects the reactor and the eudiometer has no septum. The eudiometers are calibrated glass tubes with measuring volume of $800 \mathrm{ml}$. Three GL-14 nozzles were built into each eudiometer: one under for connecting to the reservoir bottles; one at the top half for discharging the gas when full; and one at the top for connecting to the reactors. The eudiometers were fixed to the sides of the metal frame, which also carried the weight of the water bath on the lower shelf, and 9 reservoir bottles on the upper shelf. Each eudiometer contains barrier solution. The 91 -litre reservoir plastic bottles collect displaced liquid (barrier solution) from the eudiometers and are connected to the eudiometers through tubes. The Barrier solution has sodium chloride $(916 \mathrm{~g} / 5 \mathrm{~L})$, citric acid $(25 \mathrm{~g} / 5 \mathrm{~L})$ and phenolphthalein as its composition. Methyl orange was used for coloration of the solution to aid easy reading. Three-layer septum was used at all bottle-plastic connection, and one-layer septum for plastic-plastic connections to ensure air tightness and prevent biogas from leaking. Biogas volume produced in the reactor was measured by the volume of displaced barriers solution. During measurement, the reservoir bottles were lowered to steady eudiometer liquid level to equalize the pressure in both the eudiometer and reactor with atmospheric level. The equilibrium level was read-off in milliliter scale $(\mathrm{ml})$ attached to the eudiometer. When the holding capacity of the eudiometer is exhausted, the gas is released through the discharge 
nozzle on the eudiometer.

For Figure 1 below, the components numbered $1-8$ are as follows: Water-bath, Thermostat, Metal frame, Eudiometers, Glass reactors, Reservoir bottles, Tubing materials and Barrier solution.

3) DESIGN OF THE EXPERIMENT (Table 3 \& Table 4).

4) PREPARING THE STOCK SOLUTION: In order to improve the nutrient availability to the population of microbes, stock solution was added. The stock solution was prepared to a concentration of 50 times the formula used in [15] and stored at $4^{\circ} \mathrm{C}$ until used for the experiments. Table 5 shows the concentration of the reagents that were added to the inoculum.

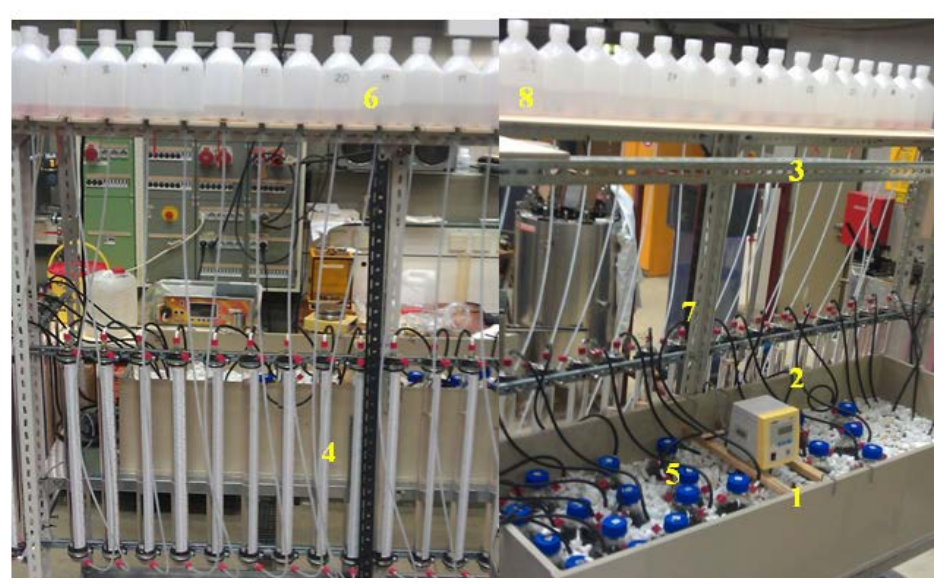

Figure 1. Experimental set-up.

Table 3. Design for predictor variables (polyphosphate salt soultion).

\begin{tabular}{cccc}
\hline Reactor-Nr & Pyro-P & Tripoly-P & Hexameta-P \\
\hline 1 & -1 & -1 & -1 \\
2 & -1 & -1 & +1 \\
3 & -1 & +1 & -1 \\
4 & -1 & +1 & +1 \\
5 & +1 & -1 & -1 \\
6 & +1 & -1 & +1 \\
7 & +1 & +1 & -1 \\
8 & +1 & +1 & +1 \\
9 (Control) & 0 & 0 & 0 \\
\hline
\end{tabular}

Source. Institute of wastewater management and water protection Lab., TUHH Germany.

Table 4. Amount of polyphosphate salts used.

\begin{tabular}{ccc}
\hline Polyphosphate Salt & \multicolumn{2}{c}{ Mass concentration (mg/l) } \\
\hline & High (+1) & Low (-1) \\
\hline $\mathrm{Na}_{5} \mathrm{P}_{3} \mathrm{O}_{10}$ Tripoly-P & 0.996 & 0.460 \\
$\mathrm{~K}_{4} \mathrm{P}_{2} \mathrm{O}_{7}$ Pyro-P & 1.300 & 0.600 \\
$\left(\mathrm{NaPO}_{3}\right)_{6}$ Hexameta-P & 1.010 & 0.468 \\
\hline
\end{tabular}

Source: Institute of wastewater management and water protection Lab., TUHH Germany. 
Table 5. Concentration of the reagents.

\begin{tabular}{ccc}
\hline Reagent & $\begin{array}{c}\text { Concentration }(\mathrm{g} / \mathrm{l}): \\
\text { Amani } \text { et al., } \mathbf{2 0 1 1}\end{array}$ & Conc. $(\mathrm{g} / \mathbf{l}) * 50$ \\
\hline $\mathrm{KH}_{2} \mathrm{PO}_{4}$ & 0.6 & 30 \\
$\mathrm{Na}_{2} \mathrm{HPO}_{4}$ & 1.33 & 66.5 \\
$\mathrm{NH}_{4} \mathrm{Cl}$ & 0.3 & 15 \\
$\mathrm{CaCl}_{2} \cdot \mathrm{H}_{2} \mathrm{O}$ & 0.11 & 5.5 \\
$\mathrm{MgCl}_{2} \cdot 6 \mathrm{H}_{2} \mathrm{O}$ & 0.1 & 5 \\
$\mathrm{NaHCO}_{3}$ & 4.0 & 200 \\
$\mathrm{FeCl}_{2}$ & 0.45 & 22.5 \\
$\mathrm{H}_{3} \mathrm{BO}_{3}$ & 0.04 & 2 \\
$\mathrm{ZnCl}_{2}$ & 0.032 & 1.6 \\
$\mathrm{CuSO}_{4} \cdot 5 \mathrm{H}_{2} \mathrm{O}$ & 0.0063 & 0.315 \\
$\mathrm{MnCl}_{2} \cdot 4 \mathrm{H}_{2} \mathrm{O}$ & 0.0295 & 1.475 \\
$\mathrm{Cystein} \mathrm{Hydrochloride}$ & 0.05 & 2.5 \\
\hline
\end{tabular}

\section{Results and Discussion}

\subsection{Characteristics of Substrate}

The principal substrate of the investigation is maize silage and the characterization results of the substrate are shown in Table 6.

\subsection{Daily and Cumulative Biogas Production}

The biogas produced per day by all the reactors ( 8 treated reactors and 1 control reactor) were measured with the eudiometer by displacement method. Table 7 below shows the result of the cumulative biogas production of each reactor for the 41 days residence time.

From Table 7, it was observed that all the treated reactors produced more biogas than the untreated reactor (control) especially reactors 1, 2, 3 and 8 . The group mean value for the cumulative biogas production among the treated reactors excluding the control experiment was calculated, in order to clearly ascertain reactors that showed significant difference. The group mean value is 4482 $\mathrm{ml}$, and comparing the production mean value with the individual production value of the reactors, it was observed that reactors $1,2,3$, and 8 productivities were above the value while reactors $4,5,6,7$ produced below this value. The result inferred that the treatments for reactors 1, 2, 3 and 8 were preferable. Furthermore the individual mean biogas production of the reactors and their respective percentage increment in relation with the control experiment were also calculated. Table 8 below shows the calculated values.

Percentage increments in biogas productivity were observed, which was as a result of the treatment with Poly-Phosphate salts. Reactor-1 that has all the Poly-Phosphate salts solution in low concentration had the most significant percentage increment of $21 \%$. 
Table 6. Characteristics of maize silage substrate. (a) Fundamental characteristics for anaerobic digestion. (b) Essential trace elements.

(a)

\begin{tabular}{cc}
\hline $\mathrm{pH}$ & $7.7 \pm 0.1$ \\
TS (\% of substrate) & $35.52 \pm 0.32$ \\
TS (\% of digestate) & $10.30 \pm 0.04$ \\
OTS (\% of TS digestate) & $74.5 \pm 0.60$ \\
Ash (\% of substrate) & $5.29 \pm 1.40$ \\
Ash (\% of digestate) & $2.63 \pm 0.06$ \\
\hline
\end{tabular}

(b)

\begin{tabular}{ccc}
\hline & $\mathrm{mg} \cdot \mathrm{kg}^{-1} \mathrm{TS}$ & $\mathrm{mg} \cdot \mathrm{l}^{-1}$ \\
\hline Molybdenum (Mo) & 1.55 & 0.01 \\
Cobalt (Co) & 1.07 & 0.01 \\
Nickel (Ni) & 3.48 & 0.03 \\
Selenium (Se) & $\mathrm{ND}$ & $\mathrm{ND}$ \\
\hline
\end{tabular}

ND means "Not Detected".

Table 7. Cumulative Biogas production for 41 days.

\begin{tabular}{cccccccccc}
\hline Day & R-1 (ml) & R-2 $(\mathrm{ml})$ & R-3 $(\mathrm{ml})$ & R-4 $(\mathrm{ml})$ & R-5 $(\mathrm{ml})$ & $\mathrm{R}-6(\mathrm{ml})$ & $\mathrm{R}-7(\mathrm{ml})$ & $\mathrm{R}-8(\mathrm{ml})$ & $\begin{array}{c}\text { Control } \\
(\mathrm{ml})\end{array}$ \\
\hline $\mathbf{1}$ & 31.7 & 28.2 & 26.2 & 26.2 & 26.2 & 28.2 & 28.4 & 22.2 & 20.1 \\
$\mathbf{1 0}$ & 608.5 & 545.6 & 585.7 & 502.9 & 506.6 & 508.7 & 493.8 & 411.4 & 482.6 \\
$\mathbf{2 0}$ & 2298.5 & 1734.4 & 1825.3 & 1676.5 & 1634.2 & 1708.8 & 1669.3 & 1262.1 & 1581.7 \\
$\mathbf{3 0}$ & 4316.2 & 3527.0 & 3459.2 & 3229.0 & 3098.8 & 3282.0 & 3125.2 & 2847.1 & 3040.1 \\
$\mathbf{4 1}$ & $\mathbf{4 9 2 7 . 3}$ & $\mathbf{4 6 0 6 . 8}$ & $\mathbf{4 5 6 1 . 8}$ & $\mathbf{4 2 5 9 . 8}$ & $\mathbf{4 1 7 6 . 6}$ & $\mathbf{4 3 4 3 . 3}$ & $\mathbf{4 3 3 6 . 6}$ & $\mathbf{4 6 4 3 . 7}$ & $\mathbf{4 0 7 1 . 6}$ \\
\hline
\end{tabular}

Table 8. Mean Biogas production per day.

\begin{tabular}{ccc}
\hline Reactor & Individual Mean Production (ml/day) & \% Increment \\
\hline R-1 & 120.2 & 21.0 \\
R-2 & 112.4 & 13.1 \\
R-3 & 111.3 & 12.0 \\
R-4 & 103.9 & 4.6 \\
R-5 & 101.9 & 2.6 \\
R-6 & 105.9 & 6.7 \\
R-7 & 105.8 & 6.5 \\
R-8 & 113.3 & 14.1 \\
Control & 99.3 & reference \\
\hline
\end{tabular}

\subsection{Degradation Rate of the Volatile Fatty Acids (VFAs)}

One of the major known problems in anaerobic digestion technology is the low degradation rate of the volatile fatty acids (VFAs) produced by the acidogens. Accumulation of the VFAs could lead to the inhibition of the activities of the 
methanogens and cellulose degradation, and ultimately reactor failure [5] [9]. So it was established that low degradation rate adversely affect the biogas productivity as well as the methane yield. The result in Table 9 shows that the treated reactors had improved degradation rate than the control. It can be inferred that the acetogens had an initial energy source from the poly-phosphate hydrolysis to activate the VFAs in the treated reactors; hence, providing acetate, $\mathrm{CO}_{2}$ and $\mathrm{H}_{2}$ for the slow-growing methanogens. Table 9 below shows the average degradation rate of the reactors and the percentage increment of the treated reactors in relation to the control reactor.

The mean average degradation rate of the treated reactors excluding the control reactor is 8.71. Comparatively, reactors number 1, 2, 3 and 8 performed above this mean value, indicating significant degradation rate. This effect is clearly seen or evident in the percentage increment of the degradation rate when compared with that of the control experiment. Reactor Nr-1 exhibited the highest/best VFAs degradation rate of $47 \%$ with respect to the reactor 9 (control reactor/reference).

\subsection{The Specific Methane Content}

The methane yield is a direct consequence of the degradation rate of the VFAs. Once the VFA accumulation goes beyond the endurance of acetogenesis bacteria $(\mathrm{AB})$ in an anaerobic digestion, the activities of $\mathrm{AB}$ would be repressed, the $\mathrm{pH}$ of the reactor would decrease rapidly and the whole culture would become unsuitable for the methanogenesis bacteria (MB) growth. Thus, as the activities of the methanogenic bacteria become repressed, the methane yield will decrease, leading to further accumulation of the VFAs and finally the complete cessation of the methane production. In a nut shell the MB quantity has a direct correlation with the methane yield.

From Table 10, it can be inferred that the treated reactors produced more methane $\left(\mathrm{CH}_{4}\right)$ than the untreated reactor (control experiment). But reactors $\mathrm{Nr}$. $1,2,3$, and 8 had pronounced specific methane yield improvement than the other treated reactors. This buttresses the fact that degradation rate has a direct correlation with the specific methane yield, because these reactors were the ones that showed significant improvement in their degradation rates. Table 10 also shows the percentage increment of the specific methane content of the treated reactors in relation to the untreated reactor (control experiment).

Table 9. Degradation rate performance of the reactors.

\begin{tabular}{cccccccccc}
\hline Reactor & R-1 & R-2 & R-3 & R-4 & R-5 & R-6 & R-7 & R-8 & Control \\
\hline $\begin{array}{c}\text { Average } \\
\text { degradation rate } \\
\text { (mol/L.day) }\end{array}$ & 9.62 & 9.60 & 9.03 & 7.92 & 7.77 & 8.04 & 8.44 & 9.25 & 6.54 \\
\% Increment & 47.16 & 46.78 & 38.09 & 21.11 & 18.86 & 23.03 & 29.05 & 41.50 & reference \\
\hline
\end{tabular}


Table 10. Specific methane yield of the biogas.

\begin{tabular}{cccccccccc}
\hline Reactor & $\mathbf{1}$ & $\mathbf{2}$ & $\mathbf{3}$ & $\mathbf{4}$ & $\mathbf{5}$ & $\mathbf{6}$ & $\mathbf{7}$ & $\mathbf{8}$ & Control \\
\hline $\begin{array}{c}\text { Methane } \\
\text { content (ml) }\end{array}$ & 225.8 & 217.88 & 209.27 & 200.11 & 195.22 & 201.31 & 205.11 & 211.64 & 183.50 \\
$\begin{array}{c}\text { \% Increment } \\
23.05\end{array}$ & 18.74 & 14.04 & 9.05 & 6.39 & 9.70 & 11.78 & 15.33 & Reference \\
\hline
\end{tabular}

\subsection{Polyphosphate Hydrolysis}

This study investigated the influence of polyphosphate hydrolysis on the degradation rate of high VFA concentration in anaerobic digestion. From the results obtained, it was evident that the hydrolysis of the Poly-P provided the initial energy needed for the activation/degradation of the VFAs. Reactors (Nr-1, 2, and 3) with low concentration of the polyphosphate salt combination and reactor $\mathrm{Nr}-8$ with high concentrations for the three polyphosphate salts combination performed better than others. These results are in consonance with the fundamental knowledge from the literature review that the hydrolysis of Poly-P salts is concentration, $\mathrm{pH}$, temperature and catalyst dependent. The hydrolysis of Polyp-P is usually slow; this study lasted for 41 days.

\section{Conclusion}

Volatile fatty acids are the most important intermediate products in anaerobic digestion, and their degradations are extremely complicated thermodynamically [15]. Syntrophic anaerobic digestion of VFAs using Maize silage as the inoculum and base substrate, with initial supplement of VFAs (Na-propionate, Na-butyrate and $\mathrm{Na}$-acetate) in order to increase the VFA concentration at the start of the experiment in a llitre batch bioreactor at mesophilic temperature of $35^{\circ} \mathrm{C}$ was investigated in this study. It is important to note that emphasis was laid on the propionic acid concentration effects on the degradation process; hence the highest concentration of the individual VFA was propionate. From the results of the experiment, it was observed that the hydrolysis of the poly-P salts added were able to provide energy for the degradation of the VFAs and the initial growth of the MB. This was evident in the achieved percentage increment on degradation rate of the VFAs of the treated reactors when compared with the control experiment (reactor Nr-9), and also on the improved cumulative biogas productivity and specific methane yield.

\section{Acknowledgements}

The authors would like to acknowledge the following persons; Dr. Ezebuiro Nwagbo Christpeace (PhD) and Prof. Dr. Ina Korner for their supervisory roles that made this research a huge success. Also my thanks go to the Institute of Wastewater Management and Water Protection, Technical University of Hamburg, Harburg Germany for making its laboratories available to carry-out this study. 


\section{References}

[1] Gallert, C. and Winter, J. (2002) Solid and Liquid Residues as Raw Materials for Biotechnology. Naturwissenschaften, 89, 483-496. https://doi.org/10.1007/s00114-002-0372-5

[2] Fayyaz, A.S., Qaisar, M., Mohammad, M.S., Arshid, P., Saeed, A.A., (2014) Microbial Ecology of Anaerobic Digesters: The Key Players of Anaerobiosis. The Scientific World Journal, 10, 21.

[3] Zieminski, K. and Frac, M. (2012) Methane Fermentation Process as Anaerobic Digestion of Biomass: Transformations, Stages and Microorganisms. African Journal of Biotechnology, 11, 4127-4139.

[4] Björnsson, L., Murto, M. and Mattiasson, B. (2000) Evaluation of Parameters for Monitoring an Anaerobic Co-Digestion Process. Applied Microbiology and Biotechnology, 54, 844-849. https://doi.org/10.1007/s002530000471

[5] Schmidt, J.E. and Ahring, B.K. (1995) Interspecies Electron Transfer during Propionate and Butyrate Degradation in Mesophilic Granular Sludge. Applied and Environmental Microbiology, 61, 2765-2767.

[6] Gallert, C. and Winter, J. (2005) Bacterial Metabolism in Wastewater Treatment Systems. In: Jördening, H.J. and Winter, J., Eds., Environmental Biotechnology, Concepts and Applications, Wiley-VCH, Weinheim, 1-48. https://doi.org/10.1002/3527604286.ch1

[7] Griffin, M.E., McMahon, K.D., Mackie, R.I. and Raskin, L. (1998) Methanogenic Population Dynamics during Start-Up of Anaerobic Digesters Treating Municipal Solid Waste and Biosolids. Biotechnology and Bioengineering, 57, 342-355. https://doi.org/10.1002/(SICI)1097-0290(19980205)57:3<342::AID-BIT11>3.0.CO;2 -I

[8] De Bok, A.F.M., Plugge, C.M. and Stams, A.J.M. (2004) Interspecies Electron Transfer in Methanogenic Propionate Degrading Consortia. Water Research, 38, 1368-1375. https://doi.org/10.1016/j.watres.2003.11.028

[9] Siegert, I. and Banks, C., (2005) The Effect of Volatile Fatty Acid Addition on the Anaerobic Digestion of Cellulose and Glucose in Batch Reactors. Process Biochemistry, 40, 3412-3418. https://doi.org/10.1016/j.procbio.2005.01.025

[10] Liu, F.H., Wang, S.B., Zhang, J.S., Zhang, J., Yan, X., Zhou, H.K., Zhao, G.P. and Zhou, Z.H. (2009) The Structure of the Bacterial and Archaeal Community in a Biogas Digester as Revealed by Denaturing Gradient Gel Electrophoresis and 16S rDNA Sequencing Analysis. Journal of Applied Microbiology, 106, 952-966. https://doi.org/10.1111/j.1365-2672.2008.04064.x

[11] Schink, B. and Stams, A.J.M. (2005) Syntrophism among Prokaryotes. In: Dwork, M., Ed., The Prokaryotes: An Evolving Electronic Resource for the Microbiological Community, 3rd Edition, Springer, New York, 309-335.

[12] Schink, B. (1997) Energetics of Syntrophic Cooperation in Methanogenic Degradation. Microbiology and Molecular Biology Reviews, 61, 262-280.

[13] Schink, B. and Stams, A.J.M. (2001) Syntrophism among Prokaryotes. In: Dworkin, M., Falkow, S., Rosenberg, E., Schleifer, K.-H. and Stackebrandt, E., Eds., The Prokaryotes: An Evolving Electronic Resource for the Microbiological Community, 3rd Edition, Springer Verlag, New York.

[14] Ezebuiro, N.C. (2012) Institute of Waste-Water Management and Water Protection. TUHH, Hamburg, Germany.

[15] Amani, T., Nosrati, M., Mousavi, M.S. and Kermanshahi, R.K. (2011) Study of Syn- 
trophic Anaerobic Digestion of Volatile Fatty Acids Using Enriched Cultures at Mesophilic Conditions. International Journal of Environmental Science and Technology, 8, 83-96. https://doi.org/10.1007/BF03326198 